\title{
COMPARISON OF OIL/WATER SEPARATING EFFICIENCY OF OLEOPHOBIC MEMBRANES BASED ON FLUORINE CONTAINING AND FLUORINE NON-CONTAINING COATINGS
}

\author{
F.R. Sultanov ${ }^{1,2, *}$, Ch. Daulbayev ${ }^{1,2}$, B. Bakbolat ${ }^{1,2}$, A. Zhurintayeva ${ }^{1}$, \\ O.Daulbayev $^{3}$ and Z.A. Mansurov ${ }^{1,2}$ \\ ${ }^{1}$ al-Farabi Kazakh National University, al-Farabi Ave., 71, 050040, Almaty, Kazakhstan \\ ${ }^{2}$ Institute of Combustion Problems, BogenbayBatir str., 172, 050012, Almaty, Kazakhstan \\ ${ }^{3}$ Joint Institute for Nuclear Research, Joliot-Curie str., 6, 141980, Dubna, \\ Moscow region, Russian Federation \\ *E-mail: fail_23@bk.ru
}

\begin{abstract}
The investigationresults presented in this article are focused on the influence of the compositionof coatings, which are used for obtaining of membranes, on their oil/water separating ability. To obtainmembranes of a special type of wettability, two compositions were chosen: fluorine-containing coating, which is based on poly(diallyldimethylammonium chloride)/pentadecafluorooctanoic acid and particles of $\mathrm{SiO}_{2}\left(\mathrm{PDDA} / \mathrm{PFOA} / \mathrm{SiO}_{2}\right)$ and coating without fluorine, which is based on hydrolyzed methyltriacetoxysilane. It is found that obtained membranes are hydrophilic, but depending onthe composition of their coating, they areoleophobic to different types of organic liquids. In particular, membranes coated with PDDA/PFOA/SiO 2 possess strong oleophobicity to polar organic liquids of low density - kerosene, while membranes coated by hydrolyzed methyltriacetoxysilane are highly oleophobic to more dense organic liquids - vacuum pump and rapeseed oils.
\end{abstract}

Keywords: Membranes, Mesh, Oleophobic, Hydrophilic, Oil/Water, Separation

(C) RASĀYAN. All rights reserved

\section{INTRODUCTION}

The oil contains a wide range of pollutants in various concentrations. Cases of oil spills in the aquatic environment in large volumes showed their negative impact on flora and fauna representatives ${ }^{1-4}$. Besides oil spills, there is other factorscausing pollution of water: an increase in theamount of oil containing industrialwastewater as well as leakages of organic solvents such as benzene, toluene, chloroform, dichloroethane, etc ${ }^{5-6}$.The need for removing oil to obtain clean water is one of the main issues of today science and technology. A large number of methods for oil/water separation have been developed in recent years, among them are absorption, floatation, flocculation and membrane filtration ${ }^{7-15}$. Membrane filtration is regarded as one of the most efficient methods since its efficiency completely depends on the nature of the applied membrane.

Membrane separation technology is one of novel high-performance technologies that has been developing rapidly in recent decades. This separation method is widely used in chemical, textile, pharmaceutical, food and other fields of industries ${ }^{16-19}$. The advantages of membrane technology are that they are not subjected to fouling, operate without adding chemicals, are characterized by lower energy consumption, easy to handle, has well-organized technological processes, high separation efficiency and no pollution ${ }^{20}$. Membranes refer tomaterials which are used for their production: ceramic, which are based on silicon, titania, alumina, etc.; polymer-based-polysulfone, polyamide, polytetrafluoroethylene, difluoride of polyvinylidene, etc.; metallic - palladium, silver, etc.; carbon nanomaterials containing - graphene oxide,

Rasayan J. Chem., 12(3), 1091-1097(2019)

http://dx.doi.org/10.31788/RJC.2019.1235254

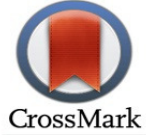


carbon nanotubes and nanofibers, fullerenes. ${ }^{21-29}$ Depending on the initial materials, membranes may possess different properties: type of surface wettability (hydrophilic, oleophilic), dye-biodegradation, anti-fouling, self-cleaning effects. The presence of carbon nanomaterials makes a great impact on water purification ability of membranes thanks totheir outstanding properties such as fast adsorption, high surface area, stability to chemical, thermal treatment, as well as mechanical stability.

The process of formation of oleophobic surfaces without using fluorinated chemicals is much complicated,therefore they are often used for obtaining hydrophilic and oleophobic membranes. However, there are growing concerns about theinfluence of fluorocarbons on the environment ${ }^{30-33}$. In this regard, the aim of this research is to study the efficiency of oil/water separating ability of hydrophilic-oleophobic membranes based on stainless steel meshes 200 , which are coated by two principally differentin their chemical compositions coatings: fluorine-containing coating, which is based on poly(diallyldimethylammonium chloride)/pentadecafluorooctanoic acid and particles of $\mathrm{SiO}_{2}\left(\mathrm{PDDA} / \mathrm{PFOA} / \mathrm{SiO}_{2}\right)$ and a coating without fluorine which is based on products of hydrolyses and condensation of methyltriacetoxysilane.

\section{Materials and Methods}

\section{EXPERIMENTAL}

Poly(diallyldimethylammonium chloride) (PDDA) (molecular weight $100000 \mathrm{~g} / \mathrm{mol}, 35 \%$ aqueous solution), pentadecafluorooctanoic acid (PFOA), $\mathrm{SiO}_{2}$ nanoparticles (average particle size $2 \mu \mathrm{m}$ ), methyltriacetoxysilane (98\%) were purchased in Sigma Aldrich and used without purification.

\section{Synthesis of Fluorine-Containing Membranes}

The oleophobic coating was synthesized as described $\mathrm{in}^{34}$. Principally, $0.1 \mathrm{~g}$ of $\mathrm{SiO}_{2}$ nanostructured spherical particles were ultrasonically dispersed in $35 \mathrm{ml}$ of aqueous solution of PDDA $(1 \mathrm{mg} / \mathrm{ml})$ with further dropwiseaddition of $8 \mathrm{ml}$ of $0.1 \mathrm{M}$ aqueous solution of PFOA into the mixture continuously stirring with formation of precipitate due to coordination of anions of PFOA with quaternary amine groups of PDDA. The resulting precipitate was washed out with distilled water and then dried in the air. Then PDDA/PFOA/SiO ${ }_{2}$ precipitate was dissolved in ethanol $(90 \%)$ and pre-cleaned meshes were immersed intothe solution and subsequently driedat room temperature. This procedure was repeated several times until membranes with thedesired properties were obtained.

\section{Synthesis of Membranes Non-containing Fluorine}

Methyl and silanol groups, which are responsible for hydrophilicity and oleophobicity of membranes, respectively, were obtained by hydrolyzes and condensation of methyltriacetoxysilane in the presence of $0.1 \mathrm{M}$ hydrochloric acid under ultrasonic treatment for 15 minutes in an ice bath. Pre-cleaned meshes were immersed in the resulting solution and subsequently dried at $60^{\circ} \mathrm{C}$ for 2 hours. This procedure was repeated several times until membranes with thedesired properties were obtained.

\section{Study of Hydrophilicity and Oleophobicity of Membranes}

The degree of hydrophilicity and oleophobicitywas studiedbymeasuring the contact angle between the surface of theobtained membrane and a drop of liquid (water or organic liquid). The type of wettability of the obtained membrane was determined using the value of the wetting angle.

\section{Study ofthe Surface Morphology of Membranes by SEM}

The investigations on the surface morphology of theobtained samples were carried out on a microscope QUANTA 3D 200i (FEI, USA) with $15 \mathrm{kV}$ accelerating voltage. For thisthe sample was attached to a copper holder using a conductive adhesive or tape.

\section{Study of Membranes Oil/Water Separation Ability}

The ability of obtained membranes to separate oil and water wasstudied on aself-assembled setup consisting of two screwed metallic stubs and attached to themglass tubes for visualization of the process. Membranes wereplaced into the space between the stubs and rubber sealed from both sides (Fig.-1). 
RASĀYAN J. Chem.

Vol. 12 | No. 3 |1091 - 1097| July - September | 2019

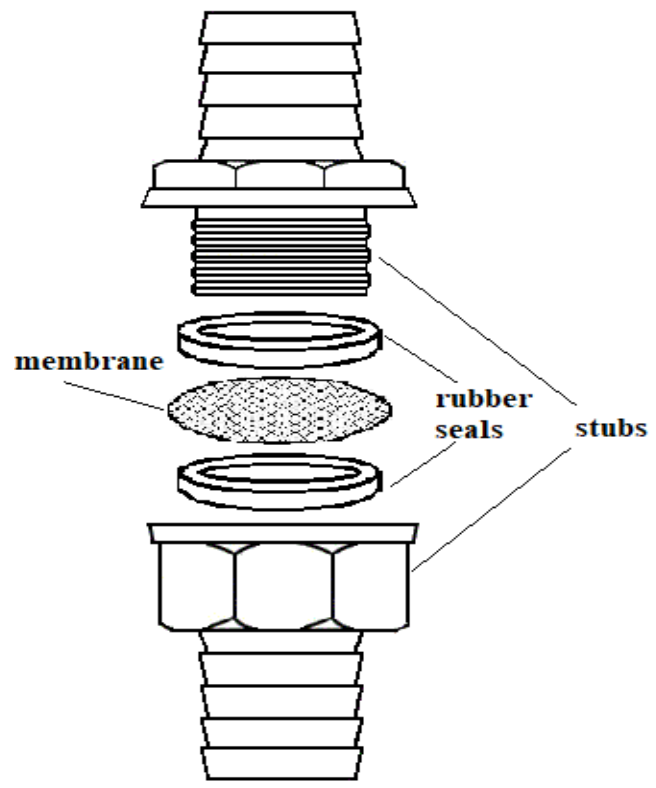

Fig.-1: Schematic Illustration of a Self-assembled Setupto Study Oil/Water Separation Efficiency of Membranes

A mixture of water and organic liquid is pouredinto the setup from the top with subsequent stratification of liquids by densities. In case of separation of water and organic liquids of lower density, water stratifies to the bottom, contacts and wets the membrane subsequently fluxingthrough it due to membrane's surface hydrophilicity, gravitational forces and pressure of the column of liquids. The volume of separated water, the rate of water flux through the membrane and the presence of organic liquid in separated water are studied during the separation process.

\section{RESULTS AND DISCUSSION}

To compareseparating efficiencies of membranes based on fluorine-containing and fluorine noncontaining coatings, composites based on PDDA/PFOA/SiO ${ }_{2}$ and methyltriacetoxysilane, respectively, were synthesized. A stainless steel meshes 200 with a diameter of wires about 66 microns were used as a substrate for membranes.

Figure-2presents the investigate results on the surface morphology of stainless steel mesh 200 without coating and theobtained membranes coated withPDDA/PFOA/SiO ${ }_{2}$ and methyltriacetoxysilane. InSEM imagesof stainless steel mesh 200 withouta coating it is seen that it is formed withintersecting wires with a smooth surface with a diameter of 65-67 microns (Fig.-2a). Coating of mesh 200 with $\mathrm{PDDA} / \mathrm{PFOA} / \mathrm{SiO}_{2}$ makes the surface rough due tothe presence of spherical particles of $\mathrm{SiO}_{2}$, which are glued on the surface of wires by a polymer. The diameter of wires has increased up to 82-86 microns after coating (Fig.-2b). In the case of coating mesh 200 by methyltriacetoxysilane,pores with the diameter ranging from 80 up to 100 microns are formed (Fig.-2c). It is also seen that the polymer is distributed along the surface of wires thus creating a film.

The degree of hydrophilicity and oleophobicity of the obtained membranes was determined by the value of wetting angle of the surface of the membrane and a drop of a studied liquid (water or organic liquid). Both membranes coated with $\mathrm{PDDA} / \mathrm{PFOA} / \mathrm{SiO}_{2}$ and methyltriacetoxysilane are highly hydrophilic, the wetting angle of their surfaces ranges from 53 to $58^{\circ}$, water passes through their structure easily, while a contact angle between organic liquid and surface of the membrane is in the range from 103 up to $126^{\circ}$. Figure-3 presents the measuring contact angle between water and surfaces of the obtained membranes. Oil/water separating efficiency of synthesized hydrophilic and oleophobic membranes was tested on a self-assembled setup presented inFig. -4 . The setup consists of two stubs and attached to the glass tubes. The membranes are placed between screwed stubs and rubber sealed on both sides. 
RASĀYAN J. Chem.

Vol. 12 | No. 3 |1091 - 1097| July - September | 2019
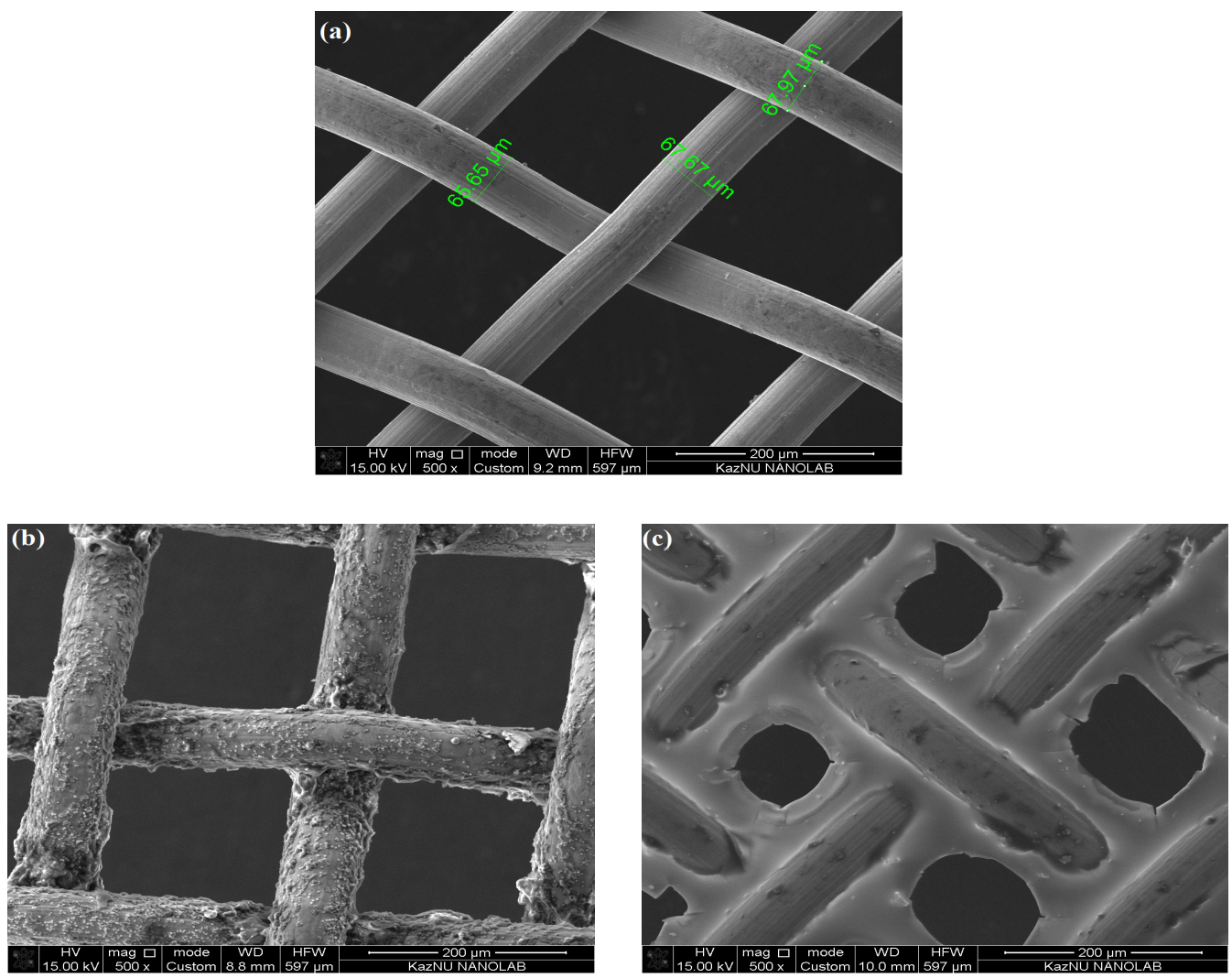

Fig.-2:SEM Images of Stainless Steel Mesh 200 without Coating (a), Coated with PDDA/PFOA/SiO Methyltriacetoxysilane (c)

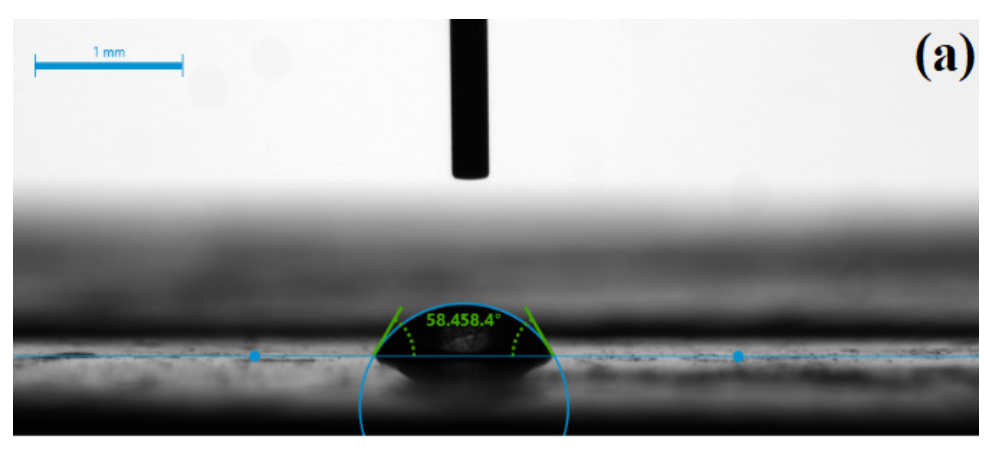

(a)

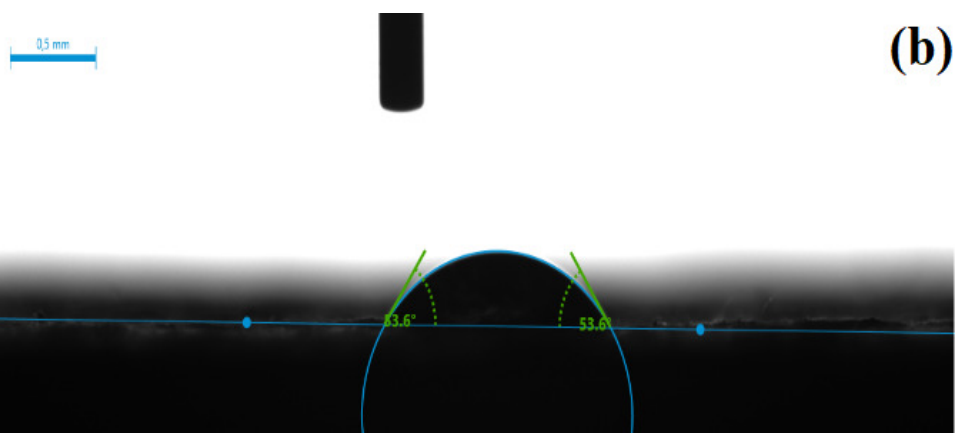

(b)

Fig.-3: Value of Wetting Angle of a Drop of Water and Surfaces of Membranes Based on PDDA/PFOA/SiO ${ }_{2}$ (a) and Methyltriacetoxysilane (b) 
A mixture of water and organic liquid is poured into the setup from the top and after stratification of liquids by densities, water contacts with the surface of membrane passing through it due to its hydrophilicity, while organic liquids remain on its surface. During testing of separation efficiencies of membranes the flux rate of the measured amount of water through it, as well as the presence of organic liquids in separated water are analyzed.

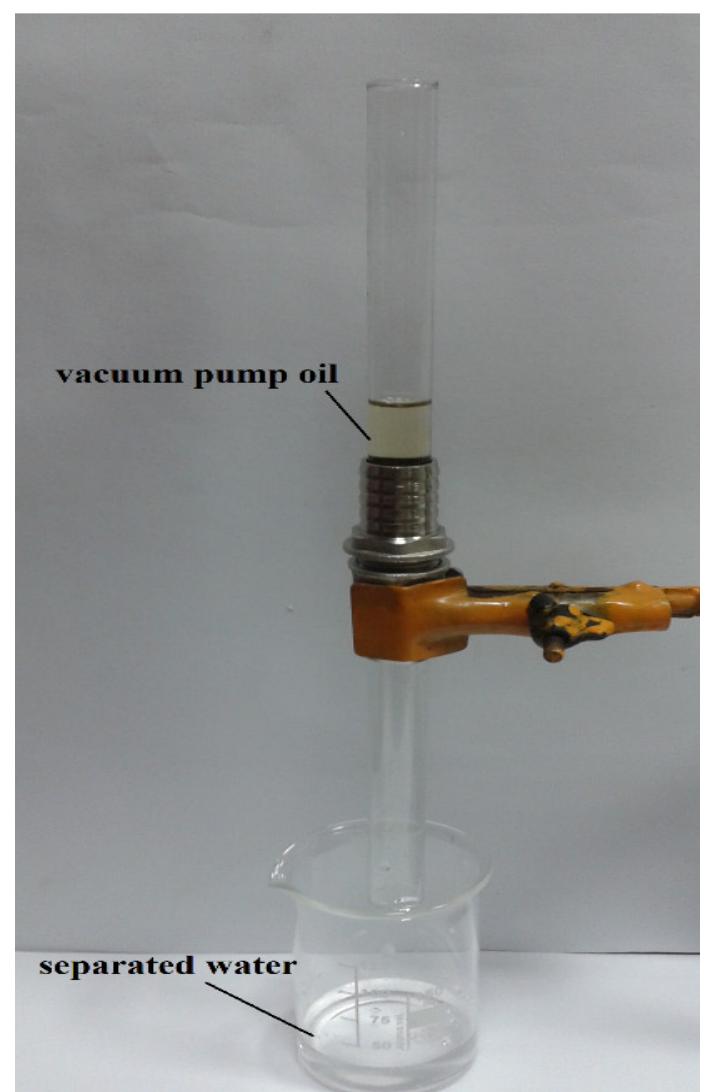

Fig.-4:Picture of a Setup for Testing Oil/Water Separating Efficiencies of Synthesized Hydrophilic and Oleophobic Membranes

The testing results onoil/water separation efficiency of synthesized membranes based on stainless steel mesh 200 coated with PDDA/PFOA/SiO ${ }_{2}$ and methyltriacetoxysilaneare summarized in the Table- 1 . The obtained membranes were tested for separation of water from organic liquids of different densities: kerosene $-0.78 \mathrm{~g} / \mathrm{cm}^{3}$, vacuum pump oil $-0.83 \mathrm{~g} / \mathrm{cm}^{3}$, rapeseed oil $-0.914 \mathrm{~g} / \mathrm{cm}^{3}$. In the Table-1it can be seen thatboth membranes are hydrophilic, the flux rate of $25 \mathrm{ml}$ of water through membrane is about 6 seconds for the membrane coated withmethyltriacetoxysilane and about 9 seconds for the coating based on PDDA/PFOA/SiO 2 . Membranes based on PDDA/PFOA/SiO $\mathrm{S}_{2}$ coating possess strong oleophobicity to organic liquids of lower density - kerosene, after 40 minutes no flux of kerosene through the membranewas observed, while it takes liquids of higher densities - $25 \mathrm{ml}$ of vacuum pump and rapeseed oils - 28 and 30 minutes to flux through the membrane. The nature of hydrophilicity and oleophobicity of membranes based on PDDA/PFOA/SiO ${ }_{2}$ may be explained by a high concentration of functional fluorine, carboxyl and quaternary ammonium containing groups.

On the other hand, membranes based on methyltriacetoxysilane coating possess strong oleophobicity to organic liquids of high density - vacuum pump and rapeseed oil, no flux of these liquids through the membrane was observed during 40 minutes waiting, while flux rate of kerosene $(25 \mathrm{ml})$ through it is about 40 minutes. Hydrophilicity and simultaneous oleophobicity of membranes based on methyltriacetoxysilane is explained by the formation of hydrophilic silanol and oleophobic methyl groups during hydrolyzes and condensation of methyltriacetoxysilane. 
RASĀYAN J. Chem.

Vol. 12 | No. 3 |1091 - 1097| July - September | 2019

Table-1:Study of the Wetting Angle and Oil/Water Separating Efficiencies ofthe Obtained Membranes

\begin{tabular}{l|c|c|c|c}
\hline \multirow{2}{*}{ Type of Membrane } & \multicolumn{3}{|c}{ Value of Wetting Angle, \%/Rate of Liquid Flux through the Membrane } \\
\cline { 2 - 5 } & Water, 25 ml & Kerosene, 25 ml & $\begin{array}{c}\text { Vacuum pump } \\
\text { oil, 25 ml }\end{array}$ & $\begin{array}{c}\text { Rapeseed oil, 25 } \\
\text { ml }\end{array}$ \\
\hline $\begin{array}{l}\text { Stainless Steel Mesh 200 } \\
\text { Coated withPDDA/PFOA/SiO }\end{array}$ & $58 / 8-9 \mathrm{sec}$. & $106 /$ no flux & $101 / 26-28 \mathrm{~min}$. & $102 / 29-30 \mathrm{~min}$. \\
\hline $\begin{array}{l}\text { Stainless Steel Mesh 200 } \\
\begin{array}{l}\text { Coated } \\
\text { withMethyltriacetoxysilane }\end{array}\end{array}$ & $53 / 5-6 \mathrm{sec}$. & $103 / 38-40 \mathrm{~min}$. & $121 /$ no flux & $126 /$ no flux \\
\hline
\end{tabular}

CONCLUSION

The influence of the nature of membrane coatingson their separating ability is described in this article. Both typesofthe obtained membranes - fluorine containing based on PDDA/PFOA/SiO ${ }_{2}$ and fluorine noncontaining based on hydrolyzed methyltriacetoxysilane are highly hydrophilic. Fluorine containing membranes possess strong oleophobicity to polar organic liquids of low density - there wasn't any flux of kerosene through the membrane, while the flux rate of denser liquids - vacuum pump and rapeseed oils of avolume of $25 \mathrm{ml}$ - through the membrane is still low, 28 and 30 minutes, respectively. In contrastto fluorine containing membranes, membranes based on hydrolyzed methyltriacetoxysilane possess strong oleophobicity to denser liquids - there weren't any fluxes of vacuum pump and rapeseed oils through it, while the flux rateof $25 \mathrm{ml}$ of kerosene is $40 \mathrm{~min}$. Both types of membranes are excellent candidates for efficient separation of water from oil under gravitational forces, but thepresence of fluorine in case of membrane based on PDDA/PFOA/SiO 2 can limit their application in the field of purification of drinking water.

\section{ACKNOWLEDGMENT}

Scientific results presented in this article were obtained in the framework of project \#AP05131745 "Obtaining of micro and nanoporous membranes of a special type of wettability for complex purification of water from organic pollutants and salts" with support of Ministry of Education and Science of the Republic of Kazakhstan.

\section{REFERENCES}

1. C.M. Reddy, J.S. Arey, J.S. Seewald, S.P. Sylva, K.L. Lemkau, R.K. Nelson, C.A.Carmichael, C.P. McIntyre, J. Fenwick, G.T. Ventura, B.A.S. Van Mooy, R.Camilli, PNAS, 109(50), 20229(2012), DOI:10.1073/pnas.1101242108.

2. T. Zhang, Q. Zhang, X. Wang, Q. Li, J. Rong, F. Qiu, RSC Adv., 5(122), 101186(2015), DOI: $10.1039 / \mathrm{C} 5 \mathrm{RA} 21132 \mathrm{H}$.

3. M. Schrope, Nature News, 472(7342), 152(2011), DOI:10.1038/472152a.

4. L. Yan, Q. Li, H. Chi, Y. Qiao, T. Zhang, F. Zheng, Adv. Compos. Hybrid Mate.r, 1(3), 567(2018), DOI:10.1007/s42114-018-0043-4.

5. J. Ge, L.A. Shi, Y.C. Wang, H.Y. Zhao, H.B. Yao, Y.B. Zhu, Y. Zhang, H.W. Zhu, H.A. Wu, S.H. Yu, Nat. Nanotechnol., 12(5), 434(2017), DOI:10.1038/NNANO.2017.33.

6. C.H. Lee, B. Tiwari, D. Zhang, Y.K. Yap, Environ. Sci.-Nano, 4(3), 514(2017), DOI: $10.1039 /$ c6en00505e.

7. F. Sultanov, B. Bakbolat, Ch. Daulbaev, M. Tulepov, S.S. Pei, Journal of Engineering Physics and Thermophysics,90(4), 826(2017), DOI:10.1007/s10891-017-1631-9.

8. D. Fragouli, A. Athanassiou, Nat. Nanotechnol.,12(5), 406(2017), DOI:10.1038/nnano.2017.63.

9. S.S. Banerjee, M.V. Jochi, R.V. Jayaram, Chemosphere, 64(6), 1026(2006), DOI:10.1016/j.chemosphere.2006.01.065.

10. R. Etchepare, H. Oliveira, A. Azevedo, J. Rubio, Sep. Pruif. Technol., 186, 326(2017), DOI:10.1016/j.seppur.2017.06.007.

11. W. Kang, L. Guo, H. Fan, L. Meng, Y. Li, J. Pet. Sci. Eng, 81, 177(2012), DOI:10.1016/j.petrol.2011.12.011.

12. C.Y. Teh, P.M. Budiman, K.P.Y. Shak, T.Y. Wu, Ind. Eng. Chem. Res.,55(16), 4363(2016), DOI:10.1021/acs.iecr.5b04703. 
13. T. Bilstad, E. Espedal, Water Sci. Technol., 34(9), 239(1996),DOI:10.1016/S0273-1223(96)00810-4.

14. M. Cheryan, N. Rajagopalan, J. Membr. Sci.,151(1),13(1998), DOI:10.1016/s0376-7388(98)00190-2.

15. B. Mi, M. Elimelech, J. Membr. Sci., 348(1-2), 337(2010), DOI:10.1016/j.memsci.2009.11.021.

16. Z. Chen, N. Ren, A. Wang, Z.-P. Zhang, Y. Shi, Water Res., 42(13), 3385(2008), DOI:10.1016/j.watres.2008.04.020.

17. C. Fersi, M. Dhahbi, Desalination, 222(1-3), 263(2008), DOI:10.1016/j.desal.2007.01.171.

18. S. Lee, Y. Kim, J. Park, H.K. Shon, S. Hong, J. Membr. Sci., 556, 238(2018), DOI: 10.1016/j.memsci.2018.04.008

19. R.M. Kirby, J. Bartram, R. Carr, Food Control, 14(5),283(2003),DOI:10.1016/S09567135(02)00090-7.

20. Ch. Zhong, G. Cao, X. Qi, J. Fu, Ch. Zhang, Filtration+Separation, 54(6), 36(2017), DOI:10.1016/S0015-1882(18)30132-0.

21. B. Hofs, J. Ogier, D. Vries, E.F. Beerendonk, E.R. Cornelissen, SeperationPurif. Technol., 79(3), 365(2011), DOI:10.1016/j.seppur.2011.03.025.

22. H. Yasuda, J. Tsai, Applied Polymer, 18(3), 805 (1974), DOI:10.1002/app.1974.070180316.

23. M.M. Pendergast, E.M. Hoek, Energy Environ. Sci., 4(6), 1946(2011), DOI:10.1039/c0ee00541j.

24. F.R. Sultanov, Ch. Daulbayev, B. Bakbolat, Z.A. Mansurov, Eurasian Journal of Physics and Functional Materials, 2(2), 104(2018), DOI:10.29317/ejpfm.2018020202.

25. Y. Yao, F. Xu, M. Chen, Z. Xu, Z. Zhu, Bioresour Technol., 101(9), 3040(2010), DOI:10.1016/j.biortech.2009.12.042.

26. S. Saga, H. Matsumoto, K. Saito, M. Minagawa, A. Tanioka, Journal of Power Source, 176(1), 16(2008), DOI:10.1016/j.jpowsour.2007.10.017.

27. Vanitha, P. Vijayalakshmi , P.K. Raji, M. Praba, Rasayan J. Chem., 12(1), 32(2019), DOI:10.31788/RJC.2019.1215041.

28. I. Gustian, Ghufira and D. Oktiarni, Rasayan J. Chem., 12(1), 284(2019), DOI:10.31788/RJC.2019.1215010.

29. N. Kusumawati, P. Setiarso, S. Muslim, Rasayan J. Chem., 11(3), 1034(2018), DOI:10.31788/RJC.2018.1133020.

30. Z.Y. Luo, K.X. Chen, Y.Q. Wang, J.H. Wang, D.C. Mo, S.S. Lyu, J. Phys. Chem. C, 120(23), 12685(2016), DOI:10.1021/acs.jpcc.6b03940.

31. T. Yu, G. Xu, W. Xiwen, J. Yang, Bioresources, 9(3), 4421(2014), DOI:10.15376/biores.9.3.44214429.

32. J. Prystupa, Toxicol. Mech. Meth., 21(2), 103(2011), DOI:10.3109/15376516.2010.542931.

33. S. Tamrakar, R. Verma, S. K. Sar and Ch. Verma, Rasayan J. Chem., 12(2), 455(2019), DOI: $10.31788 /$ RJC.2019.1225106.

34. F.R. Sultanov, Ch. Daulbayev, B. Bakbolat, Z.A. Mansurov, Eurasian Chemico - Technological Journal, 20(3), 195 (2018), DOI:10.18321/ectj721.

[RJC-5254/2019] 